\title{
Structural Properties of Small Single-Stranded Circular Nucleic Acids
}

\author{
Parth Chaturvedi, Lela Vuković*
}

Department of Chemistry and Biochemistry, University of Texas at El Paso, El Paso, TX 79968

*Authors to whom all correspondence should be addressed: lvukovic@utep.edu

\section{Electronic Supporting Information (ESI)}


Patch to create a covalent bond between 3' and 5'ends of nucleic acids:

PRES LKRI 0.0 ! Patch to join to nucleic acid segments (eg for IMAGES)

! eg: patch sega $10 \mathrm{segb} 1$

! sega should have std 3' (gene sega ... last none)

! segb should have std $5^{\prime}$ (gene segb ... first none)

! USE AUTOgen ANGL DIHE after this patch,

! but before water-generation

BOND 1O3' 2P

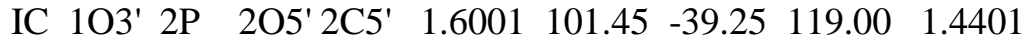

$\begin{array}{lllllll}\text { IC } 1 \text { 1O3' }^{\prime} 2 \mathrm{O} 5^{\prime} * 2 \mathrm{P} & 2 \mathrm{O} 1 \mathrm{P} & 1.6001 & 101.45 & -115.82 & 109.74 & 1.4802\end{array}$

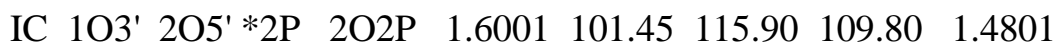

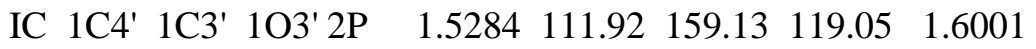

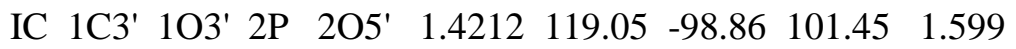

Table S1. Summary of simulation parameters used in MDFF simulations for different oligonucleotides.

\begin{tabular}{|c|c|c|c|c|c|c|}
\hline & $\begin{array}{c}(\mathrm{GT})_{3} \& \\
(\mathrm{GU})_{3}\end{array}$ & $\begin{array}{l}(\mathrm{GT})_{4} \& \\
(\mathrm{GU})_{4}\end{array}$ & $\begin{array}{l}(\mathrm{GT})_{6} \& \\
(\mathrm{GU})_{6}\end{array}$ & $\begin{array}{l}(\mathrm{GT})_{8} \& \\
(\mathrm{GU})_{8}\end{array}$ & $(\mathrm{GT})_{24}$ & $(G U)_{24}$ \\
\hline $\begin{array}{c}\text { Number }(n) \text { of dummy atoms used } \\
\text { to generate circular potential }\end{array}$ & 18 & 24 & 36 & 75 & 300 & 300 \\
\hline $\begin{array}{l}\text { Radius }(r) \text { of circular potential for } \\
\operatorname{MDFF}(\AA)\end{array}$ & $n / 3$ & $n / 3$ & $n / 3$ & $n / 5$ & $\mathrm{n} / 5$ & $\mathrm{n} / 5$ \\
\hline $\begin{array}{c}g_{\text {scale }}(\xi), \text { scaling factor for MDFF } \\
\text { potential }\end{array}$ & 0.5 & 0.5 & 0.5 & 0.5 & 1.0 & 1.0 \\
\hline Docking by colores (Situs) & yes & yes & yes & yes & no & no \\
\hline $\begin{array}{l}\text { Force constant }\left(\mathrm{kcal} / \mathrm{mol}^{2} \AA^{2}\right) \text { for } \\
\text { harmonic potential }\end{array}$ & none & none & none & 0.1 & 0.2 & 0.3 \\
\hline
\end{tabular}



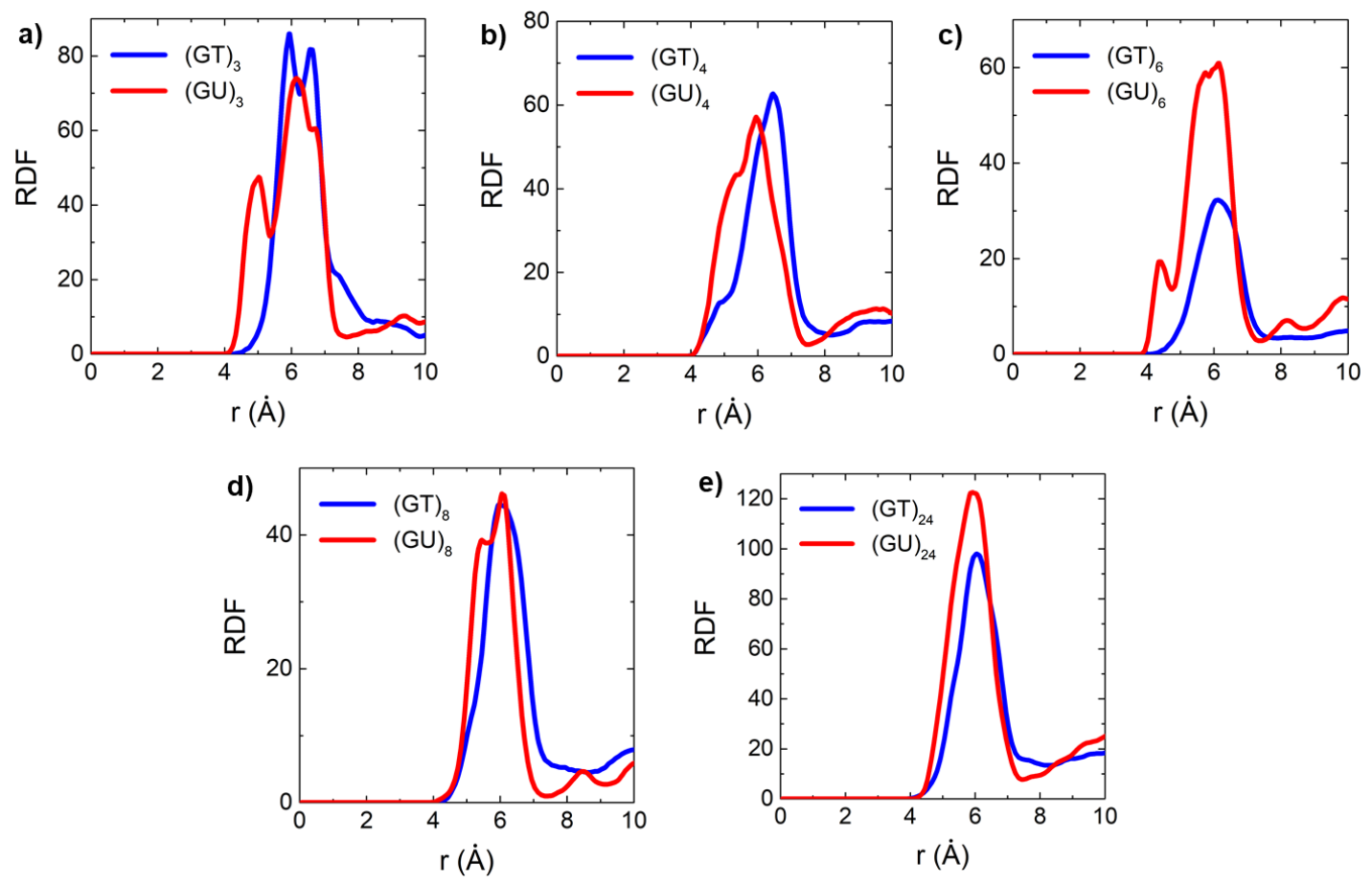

Figure S1. Radial distribution functions (RDFs) of phosphorous atoms of circNAs calculated over $1 \mu \mathrm{s}$ in MD simulations. RDFs are computed with a $10 \mathrm{~ns}$ time step. $(\mathrm{GU})_{\mathrm{n}}$ circRNAs have P-atoms that are more likely to be closer to each other than P-atoms of $(\mathrm{GT})_{\mathrm{n}}$ circDNAs, for all circNAs examined.

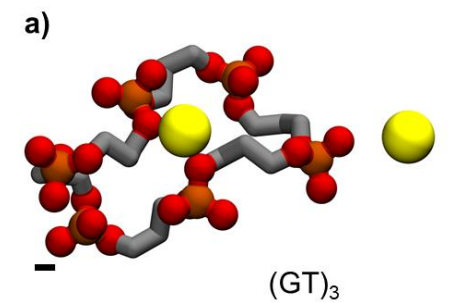

$(\mathrm{GT})_{3}$ b)



c)

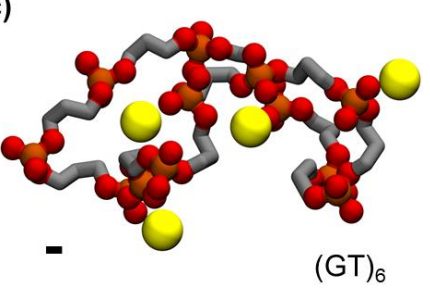

d)

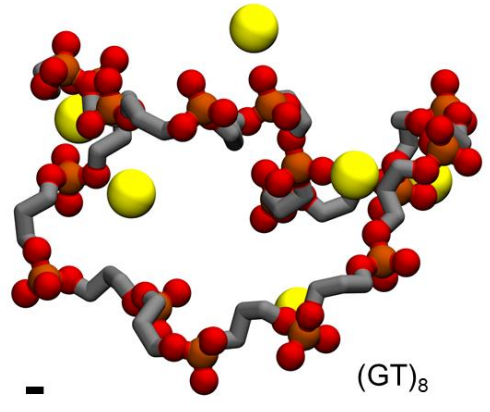

e)

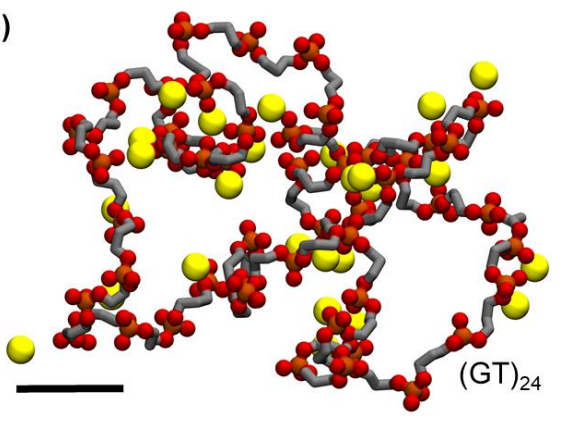

Figure S2. Sodium ions (yellow) within $4 \AA$ of $(\mathrm{GT})_{\mathrm{n}}$ circDNAs, as observed after $1 \mu \mathrm{s}$ of MD simulations. The scale bars in panels (a-d) are $1 \AA$ in length, and in panel (e) is $10 \AA$ in length. Only the backbones of circDNAs are shown (atom color scheme: C-grey, O-red, P-orange). 


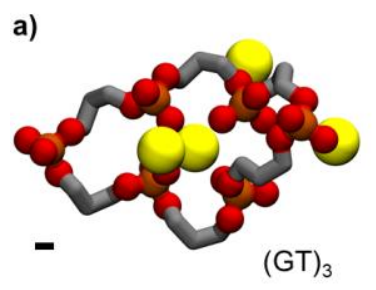

d)

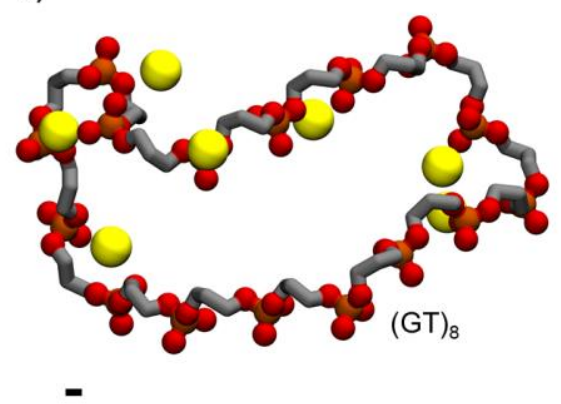

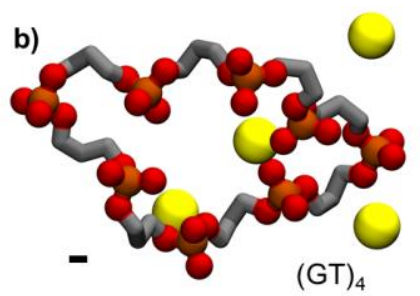

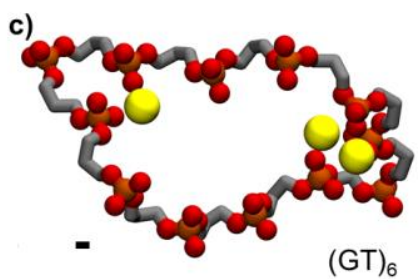

e)

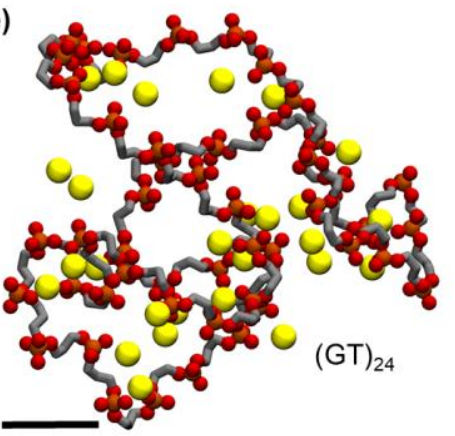

Figure S3. Sodium ions (yellow) within $4 \AA$ of $(\mathrm{GU})_{\mathrm{n}}$ circRNAs, as observed after $1 \mu$ s of MD simulation. The scale bars in panels (a-d) are $1 \AA$ in length, and in panel (e) is $10 \AA$ in length. Only the backbones of circRNAs are shown (atom color scheme: C-grey, O-red, P-orange).

a)
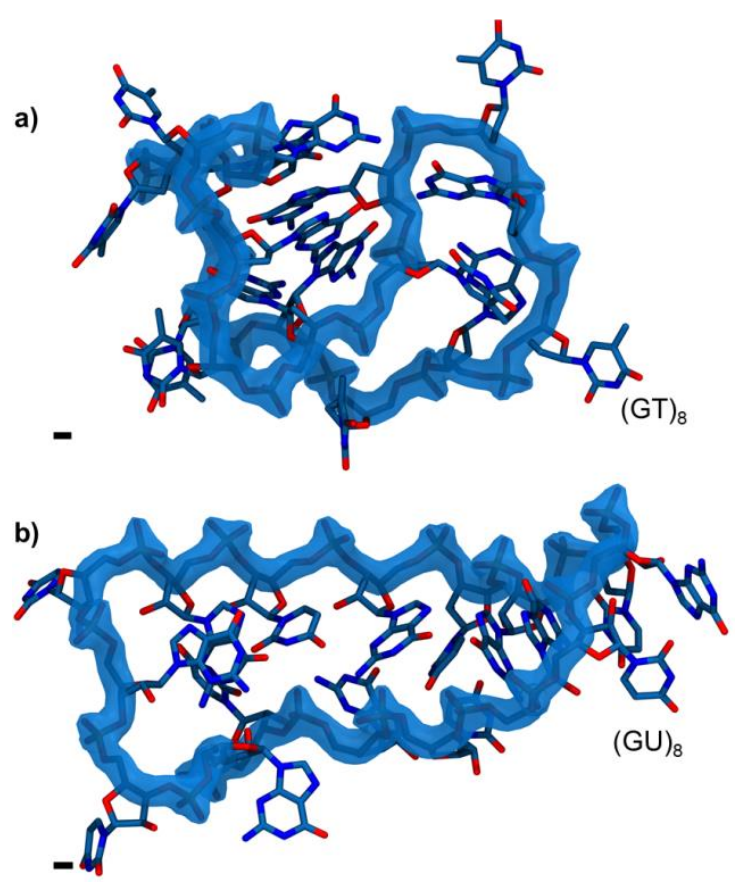

Figure S4. Conformations of circular $(\mathrm{GT})_{8}$ circDNA and $(\mathrm{GU})_{8}$ circRNAs at $1 \mu \mathrm{s}$ showing base stacking as observed in MD simulations. The scale bars in panels are $1 \AA$ in length. 

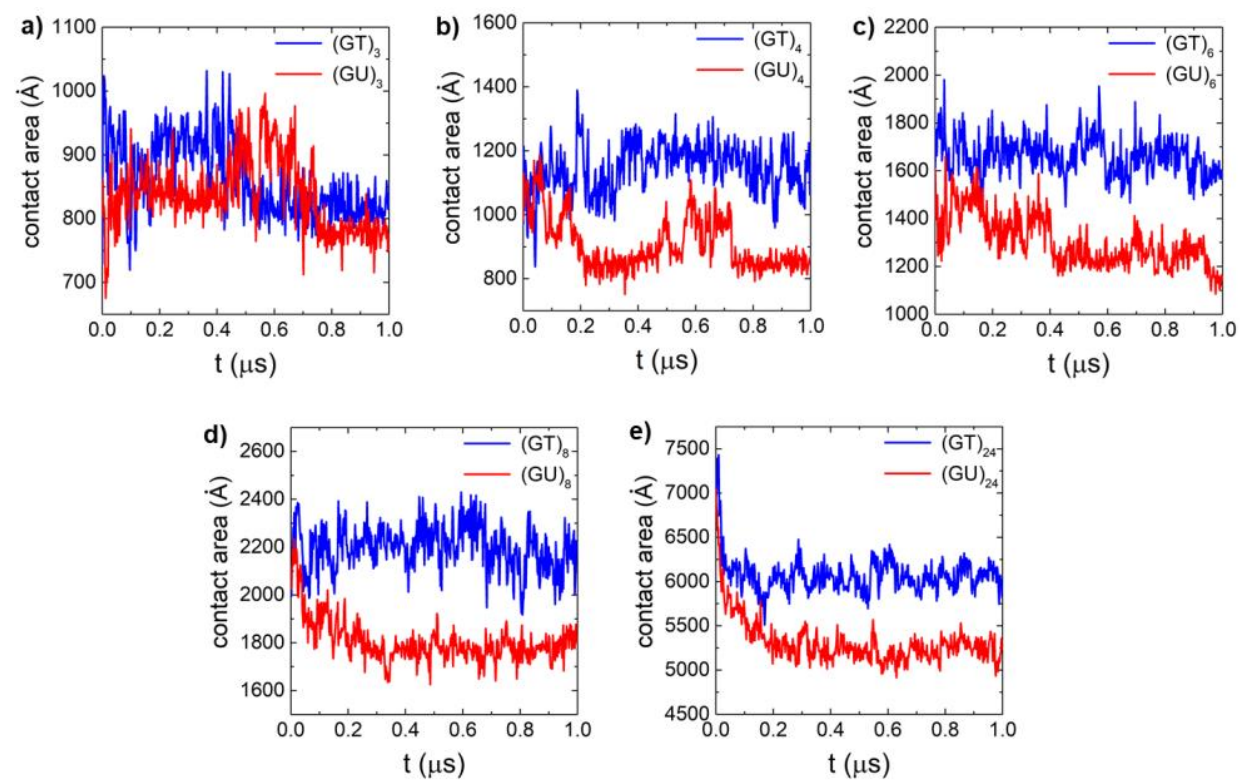

Figure S5. Contact areas between nucleotide bases and aqueous solvent for circNAs calculated over $1 \mu \mathrm{s}$ in MD simulations. The areas are computed with a 10 ns time step. $(\mathrm{GT})_{\mathrm{n}}$ circDNA bases are more waterexposed than $(\mathrm{GU})_{\mathrm{n}}$ circRNA bases in circular nucleic acids.


Figure S6. Distribution of number of contacts between four (GT) $)_{6}$ circDNA (left) and four (GU) 6 circRNAs (right) molecules, as observed in $1 \mu$ s simulations. 

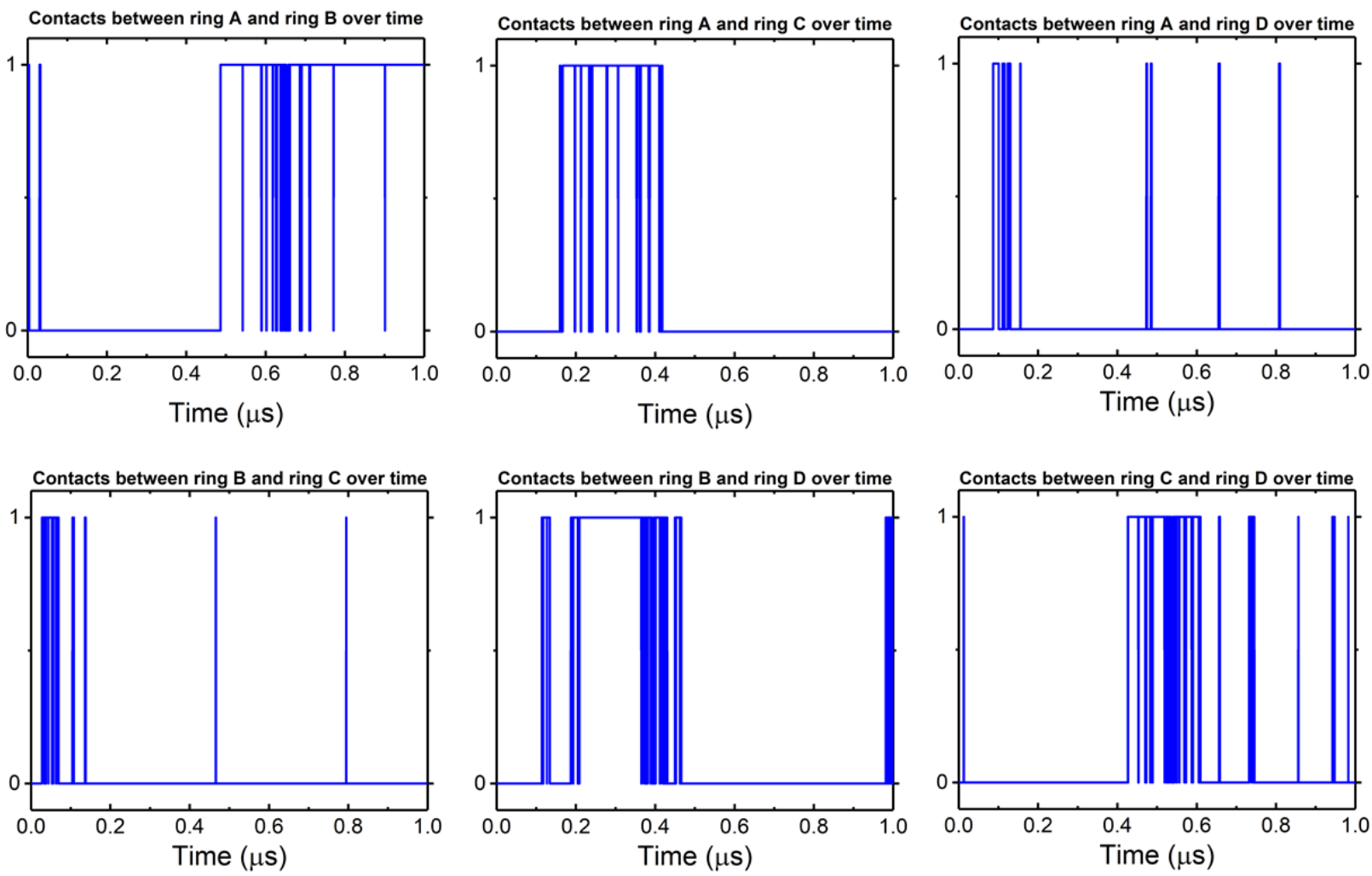

Figure S7. Contacts between pairs of circDNA- $(\mathrm{GT})_{6}$ molecules, as observed in $1 \mu$ s simulations of four circDNA-(GT) 6 molecules (at $7.9 \mathrm{mM}$ concentration). 

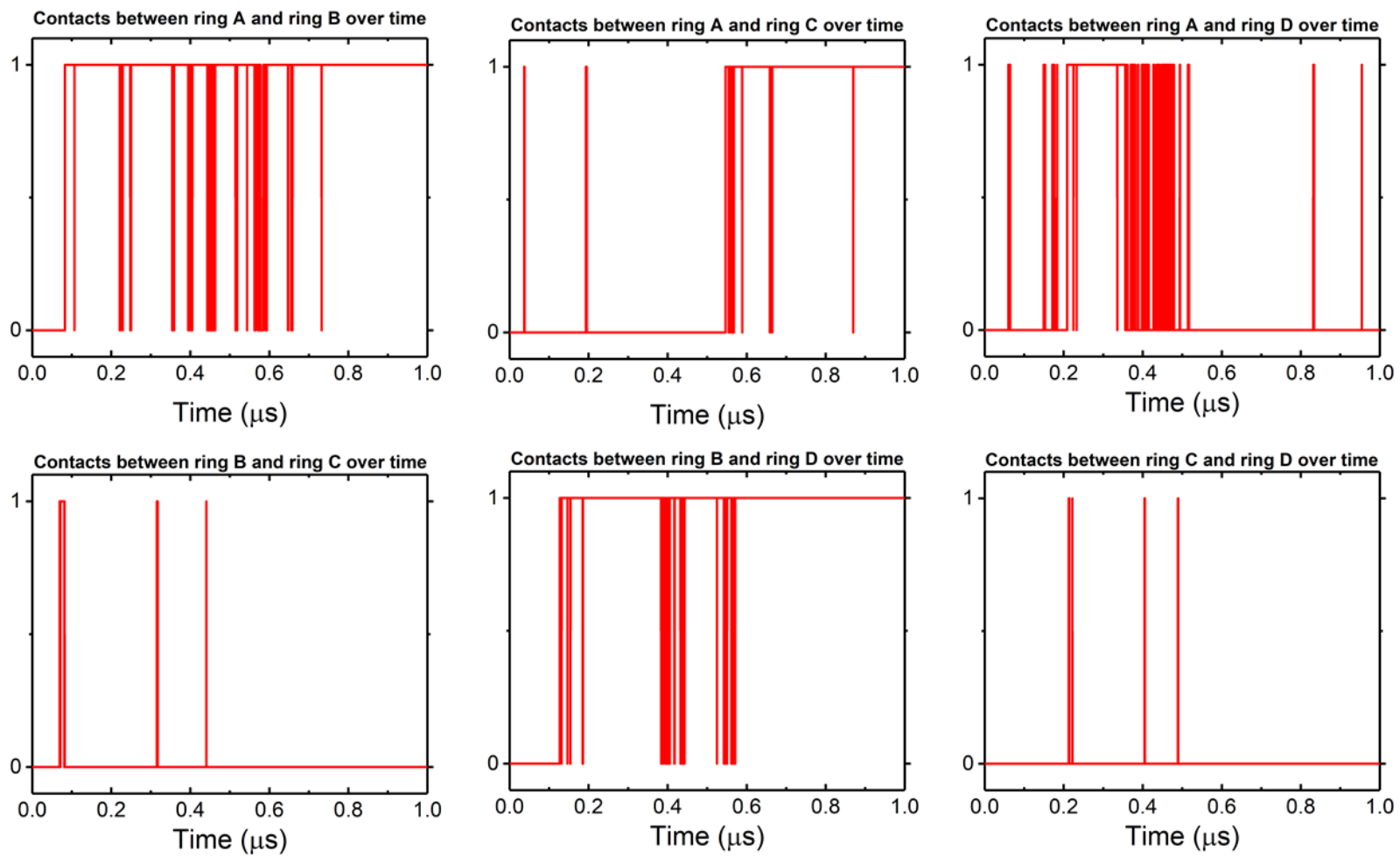

Figure S8. Contacts between pairs of circRNA- $(\mathrm{GU})_{6}$ molecules, as observed in $1 \mu$ s simulations of four circRNA-(GU) 6 molecules (at $7.9 \mathrm{mM}$ concentration).

a)

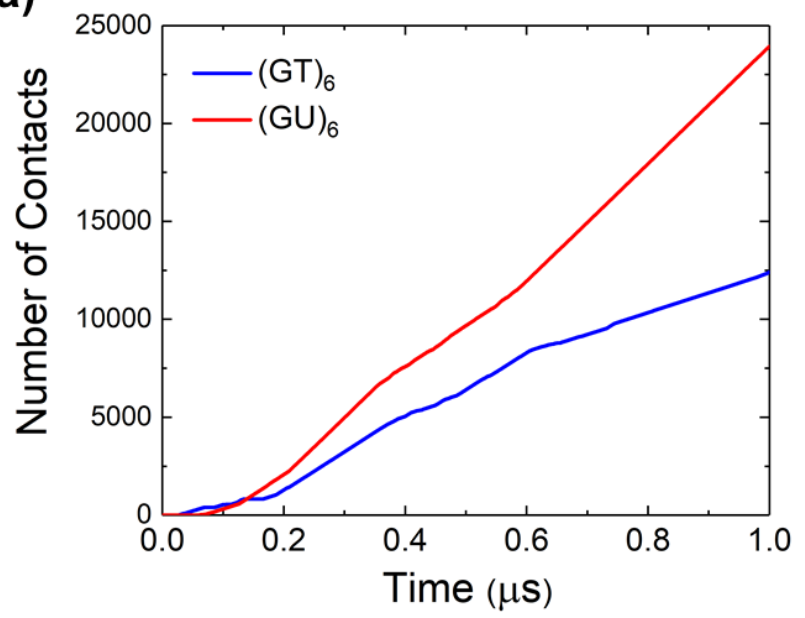

b)



Figure S9. Number of contacts between four $(\mathrm{GT})_{6}$ circDNAs or four $(\mathrm{GU})_{6}$ circRNAs (at $7.9 \mathrm{mM}$ concentration, left), and between three $(\mathrm{GT})_{6}$ circDNAs or three $(\mathrm{GU})_{6}$ circRNAs (at $5.9 \mathrm{mM}$ concentration, right). 

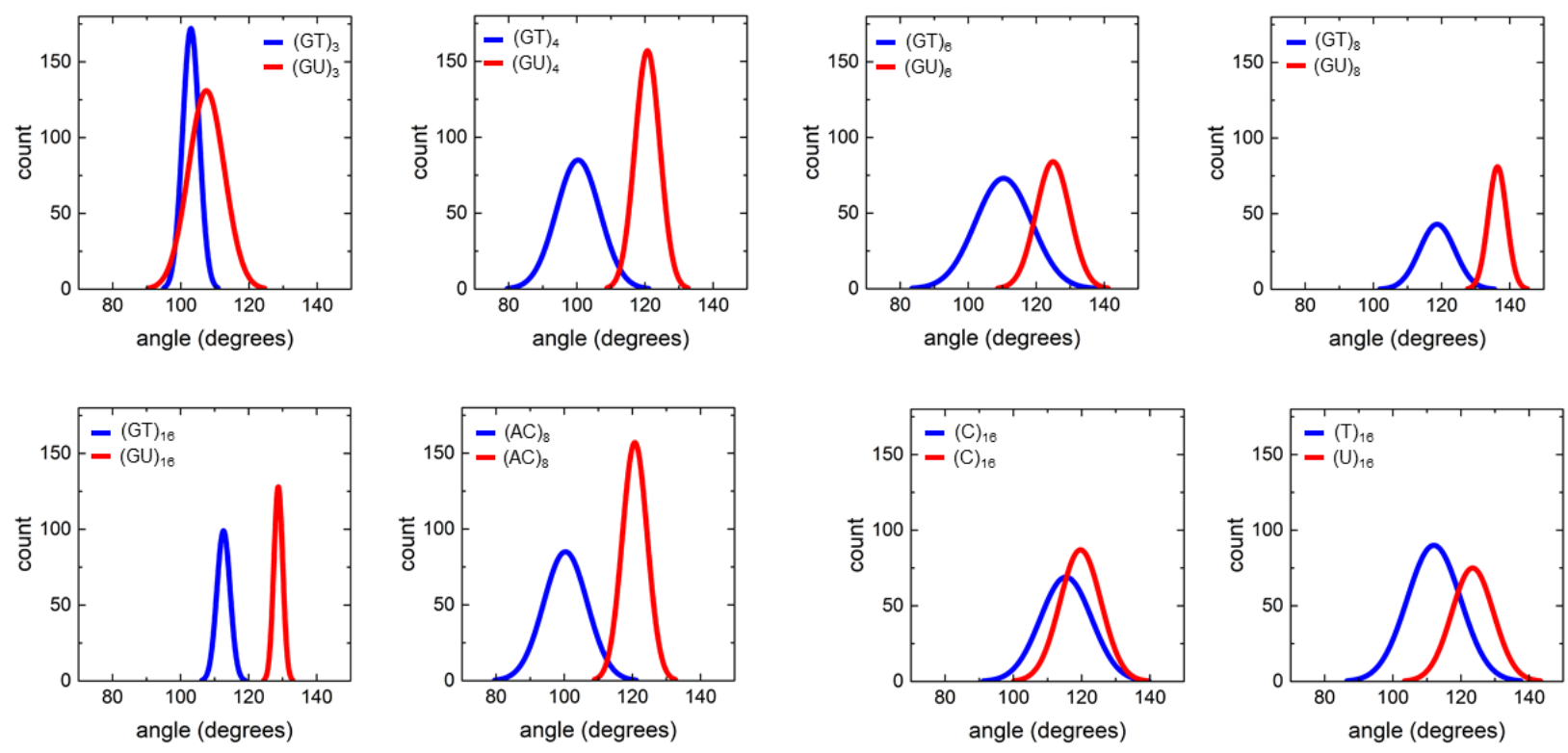

Figure S10. Distribution of phosphate angles for all P-atom triplets in the last $500 \mathrm{~ns}$ of trajectories of all circular DNA (blue) and RNA (red) molecules examined in Figure 2.
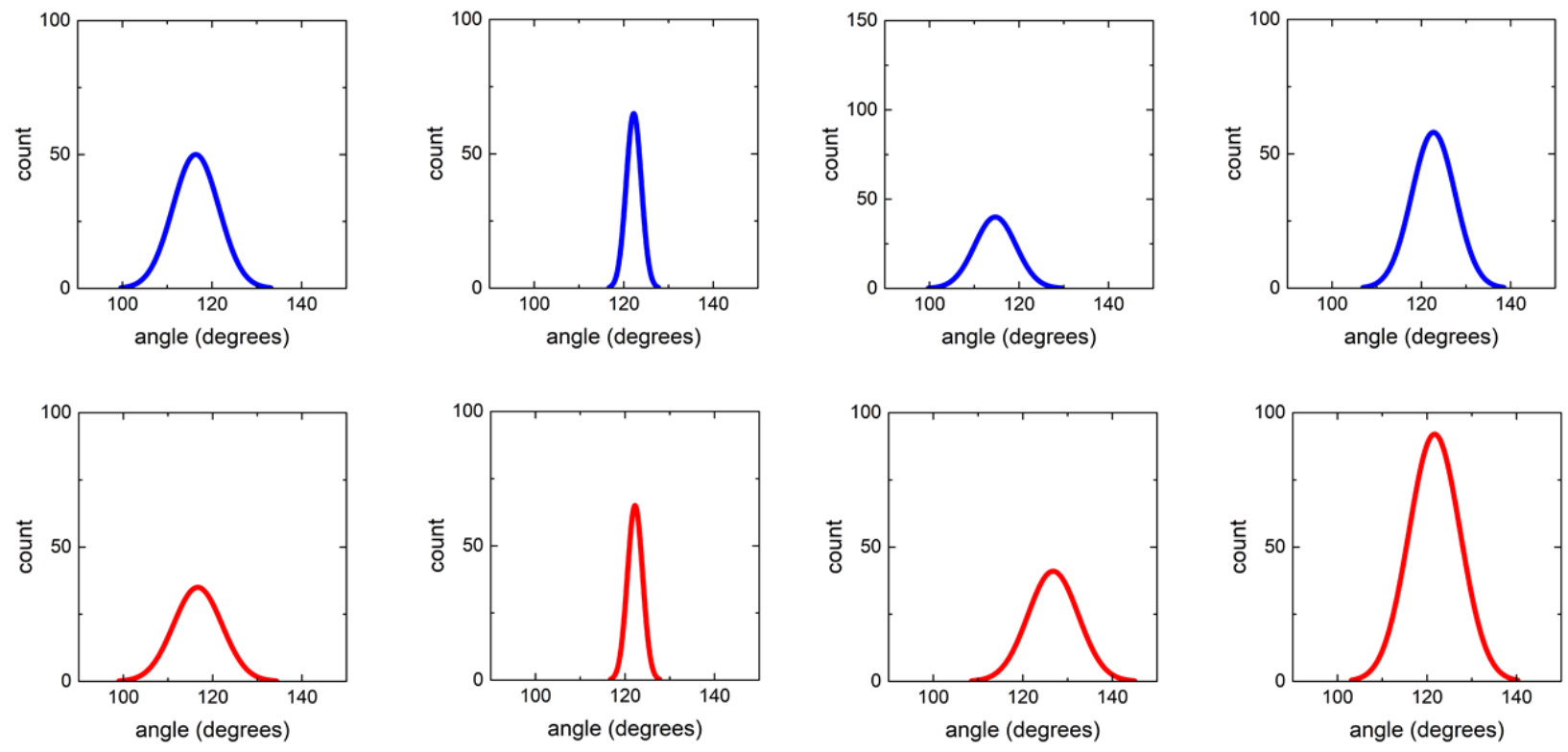

Figure S11. Distribution of phosphate angles for all P-atom triplets in the last $500 \mathrm{~ns}$ of trajectories of four circular (GT) $)_{6}$ DNA (blue) and four circular $(\mathrm{GU})_{6}$ RNA (red) molecules, examined in simulations of multiple circular molecules (shown in Figure 5). 